\title{
CARACTERIZAÇÃO DE FILMES DE MUCILAGEM DE CEREUS HILDALMANIANNUS K. SCHUM COM DIFERENTES CONCENTRAÇÕES DE GLICEROL
}

\author{
M. S. P. DAMAS, E. NIEHUES, R. C. ALVES, M. G. N. QUADRI \\ Universidade Federal de Santa Catarina, Departamento de Engenharia Química e Engenharia de \\ Alimentos \\ E-mail para contato: mara@enq.ufsc.br
}

\begin{abstract}
RESUMO - Mucilagens de diferentes fontes e seus derivados são considerados seguros para o consumo humano, sendo um potencial hidrocolóide para ser utilizado em diversas indústrias de alimentos, inclusive para elaboração de filmes comestíveis. Este composto está presente abundantemente nas cactáceas, dentro das quais se encontra o Cereus hildmaniannus K. Schum. O objetivo desse estudo foi a elaboração de filmes a partir da fração solúvel da mucilagem do fruto de $C$. hildmaniannus com diferentes concentrações de plastificante. Ensaios mecânicos (tensão de ruptura, modulo de Young e alongamento) e permeabilidade ao vapor de água foram realizados. A incorporação da proporção 1:1 de glicerol na solução aquosa a $1 \%$ de mucilagem gerou um alongamento de $71 \%$, enquanto que a mesma solução com 1:4 glicerol: mucilagem $(\mathrm{m} / \mathrm{m})$ foi de $1,8 \%$. A permeabilidade ao vapor de água aumentou linearmente nas concentrações de glicerol estudadas, variando de $0,226-0,992 \mathrm{~g} \mathrm{~mm} / \mathrm{kPa} \mathrm{h} \mathrm{m}^{2}$.
\end{abstract}

\section{INTRODUÇÃO}

Fontes naturais e renováveis tais como os polissacarídeos, lipídeos e proteínas vem sendo utilizados para o desenvolvimento de filmes e recobrimentos por minimizarem impactos ambientais resultante do uso de embalagem sintética e rígida (Ferreira et al., 2009).

Estudos foram realizados com polímeros naturais, por exemplo quitosana (Souza et al., 2013), goma de cordia (Haq et al., 2013), mucilagem de Opuntia fícus-indica (L) (Díaz et al., 2010), amido (Mali et al., 2010) e galactomananos (Cerqueira et al., 2010), por apresentarem boas propriedades formadoras de filmes e exibirem valores satisfatórios à barreira a gases, além do baixo custo e viabilidade do material elaboração de filmes.

Mucilagens são substâncias translúcidas, amorfas, poliméricas, formadas por monossacarídeos ou pela mistura deles, sendo que muitas possuem a cadeia monossacarídica combinada com ácidos urônicos. Quando hidrolisados fornecem uma mistura de açúcares e ácidos urônicos. Suas moléculas são hidrofílicas e podem ser combinadas com água para formar soluções viscosas ou géis; sabe-se da literatura que polissacarídeos lineares ocupam mais espaço e formam soluções mais viscosas do que os 
semelhantes que apresentam mesma massa molar altamente ramificados, como é o caso das mucilagens (Jani et al., 2009).

Plastificantes, em sua maior parte, são demasiadamente hidrofílicos e higroscópicos, podendo atrair moléculas de água. O seu uso em filmes e revestimentos comestíveis à base de polissacarídeos permitem o rompimento de pontes de hidrogênio, levando a um aumento da distância entre as moléculas do polímero e reduzindo a formação de regiões cristalinas em relação às amorfas (Krochta, 2002). Filmes de polissacarídeos sem plastificantes tornam-se bastante quebradiços; com o objetivo de aumentar sua flexibilidade e manuseio, o uso de plastificantes como glicerol e sorbitol vem sendo amplamente estudados. Os plastificantes influenciam todas as propriedades funcionais dos biofilmes, inclusive a permeabilidade ao vapor de água devido seu caráter hidrofílico, que na maioria das vezes aumenta linearmente com o uso de agentes plastificantes, principalmente de glicerol (Cuq et al.,1997).

Colonetti (2012) mostrou que a fração solúvel do fruto do cactus Cereus hildmaniannus K. Schum, diminuiu a tensão superficial da água até aproximadamente $55,0 \mathrm{mN} . \mathrm{m}-1$, ficando próximo dos valores encontrados na literatura para outras gomas sendo a cactácea um potencial hidrocolóide para ser utilizado em diversas indústrias inclusive para elaboração de filmes comestíveis.

Ensaios de tração são algumas das propriedades mecânicas que servem para identificar e caracterizar filmes flexíveis, bem como para avaliar a qualidade desses materiais. O ensaio de tração de um filme envolve a separação, a uma velocidade constante, de duas garras que prendem as extremidades da amostra, registrando ao longo do ensaio, a força ou a resistência que o material oferece à deformação (Sarantópoulos $e t$ al.,2002).

Com o objetivo de caracterizar filmes feitos a partir da fração solúvel precipitada do fruto de Cereus hildmaniannus K. Schum, o glicerol foi adicionado para uma melhor maleabilidade, diminuindo a fragilidade ao rompimento; a caracterização dos filmes foi feita através de ensaios mecânicos e da permeabilidade ao vapor de água.

\section{MATERIAL E MÉTODOS}

\subsection{Materiais}

A mucilagem de Cereus hildmaniannus K. Schum foi obtida no município de Zortéa no estado de Santa Catarina. Etanol (92,8 \% de pureza) e glicerina (marca Synth P.A - A.C.S) utilizados foram de grau analítico.

\subsection{Obtenção da mucilagem precipitada}

A polpa dos frutos do cactus Cereus hildmaniannus K. Schum foi submetida a processo para separação das frações solúvel e insolúvel. A polpa foi colocada em béquer com água destilada na proporção de 3:2 (m/m). Procedeu-se à agitação mecânica em agitador marca DIST, modelo DI-14MP, por 60 minutos a $300 \mathrm{rpm}$ à temperatura de $60{ }^{\circ} \mathrm{C}$, e mantida constante por chapa de aquecimento marca TECNAL, modelo TE-085. Após o tempo determinado a polpa foi peneirada em peneira de 18 mesh para uma melhor separação das frações solúvel e insolúvel. O filtrado foi resfriado à temperatura ambiente e centrifugado em 
ultra-centrífuga (modelo ProteomeLabTM XL-I da Beckman Coulter) por 20 min a 15000 rpm para melhor separação das partes sólidas ainda presentes. A fração solúvel foi precipitada com etanol na proporção de 3:1 volumes de etanol para cada volume da fração solúvel. Após cada adição de etanol, o precipitado foi separado com uso de uma peneira e no final lavado com acetona. A secagem foi realizada em estufa de secagem marca Nova Técnica (NT-513D) a $40{ }^{\circ} \mathrm{C}$ por 24 horas.

\subsection{Preparação dos filmes}

Ensaio preliminares mostraram que é possível a elaboração de filmes sem adição de plastificante. Os filmes foram preparados dissolvendo a mucilagem precipitada em solução aquosa a $1 \%(\mathrm{~m} / \mathrm{v})$ sob agitação em Ultra Turrax marca Ika Labortchnik (modelo T25 basic) a uma velocidade de $11000 \mathrm{rpm}$ por $7 \mathrm{~min}$. Em seguida adicionou-se glicerol como plastificante nas proporções: de 1:4, 1:2 e 1:1 (m/m) glicerol: mucilagem na solução aquosa de mucilagem e agitou-se por mais 5 minutos, após o que se obteve uma solução homogênea. As dispersões foram centrifugadas a $3000 \mathrm{rpm}$ por 3 minutos para remoção das bolhas, e depositadas em placas de teflon. Estas soluções foram secas a $23^{\circ} \mathrm{C}$ com circulação de ar por cerca 50 horas para formação dos filmes. Os filmes formados foram removidos das placas e colocados em dessecadores a $25^{\circ} \mathrm{C}$ e $55 \%$ de umidade relativa por pelo menos 48 horas antes da realização das análises mecânicas e permeabilidade ao vapor de água. Os experimentos foram realizados em réplicas.

\subsection{Caracterização dos filmes}

Propriedades mecânicas: A tensão de ruptura (TR), alongamento na ruptura (E) e módulo de Young (MY) foram determinados com base no método D-882 da American Society for Testing and Materials (ASTM, 2001), utilizando texturômetro TA. HD. Plus, (Stable Micro Systems), com uma célula de carga de 50 N. A distância inicial das garras foram de $50 \mathrm{~mm}$ e velocidade de tração de $0,8 \mathrm{~mm} / \mathrm{s}$. As amostras foram cortadas com 25 $\mathrm{mm}$ de largura e $100 \mathrm{~mm}$ de comprimento e analisadas em ambiente dotado de ar e condicionado à temperatura de $22 \pm 1{ }^{\circ} \mathrm{C}$ e umidade relativa de $55 \pm 3 \%$. Os resultados foram tratados estatisticamente através de Análise de variância (ANOVA) e pelo teste de Duncan a 95\% de confiança, utilizando o software Statistica 10.0 (StatSoft, Tulsa, Estados Unidos).

Permeabilidade ao vapor d'água: A permeabilidade ao vapor de água (PVA) dos filmes foi determinada por gravimetria a $25^{\circ} \mathrm{C}$, utilizando a norma da ASTM, método E96-95 (ASTM 1995). Os filmes foram cortados com $70 \mathrm{~mm}$ de diâmetro e dispostos em células de alumínio com permeação em recipiente contendo cloreto de cálcio anidro. Estas células foram colocadas em dessecadores a $25^{\circ} \mathrm{C}$ e $75 \%$ de umidade relativa. $\mathrm{O}$ ganho de massa de cloreto de anidro foi medido em intervalos de $1 \mathrm{~h}$ por 12 horas e após $24 \mathrm{~h}$ através de sucessivas pesagem em balança analítica. Assim foi possível determinar o vapor de água transferido através da película de acordo com a equação 1

$$
P V A=\frac{m_{a b} .}{t} \frac{L}{A \cdot \Delta P}
$$

Onde: 
$\mathrm{m}_{\mathrm{ab}}$ é o peso da umidade absorvida (g), t é o tempo de duração do ensaio (dias), L é a espessura $(\mathrm{mm})$, A é a área da superfície $\left(\mathrm{m}^{2}\right)$ e $\Delta \mathrm{P}$ é a diferença de pressão parcial de vapor através da película $(\mathrm{Pa})$.

Espessura dos filmes: Após período de acondicionamento, a espessura dos filmes foi obtida utilizando micrômetro digital (Digimess, IP54). A espessura foi fixada como sendo a média aritmética de 8 medidas aleatórias sobre a área do filme.

\section{RESULTADOS E DISCUSSÃO}

\subsection{Preparação dos filmes de mucilagem}

Ensaios preliminares mostraram que a preparação de filme sem adição de plastificante é possível, no entanto se apresentaram quebradiços e de difícil manuseio. Desta forma optouse pela adição do plastificante glicerol de forma a melhorar suas características. A concentração de mucilagem para a formação do filme foi de $1 \%(\mathrm{~m} / \mathrm{v})$ e a concentração de glicerol em menor quantidade foi na proporção 1:4(m/m) glicerol: mucilagem. Os filmes com maior concentração de glicerol na proporção $(1: 1 \mathrm{~m} / \mathrm{m})$ se mostraram mais flexíveis e pegajosos.

\subsection{Espessura dos filmes}

Para uma concentração constante de MP (1\%), os filmes preparados com diferentes concentrações de glicerol nas proporções 1:4, 1:2 e 1:1 glicerol: mucilagem $(\mathrm{m} / \mathrm{m})$ tiveram espessuras variando de 0,083-0,137 mm (Tabela 1). As amostras com maior concentração de glicerol adsorvem mais umidade levando a um aumento na sua espessura, devido ao processo de inchamento do filme. Estes valores de espessura foram maiores que os relatados por Ahmadi et al. e Jouki et al., e que pode ter sido devido as diferenças nas concentrações de glicerol e procedimentos de produção dos filmes. Os resultados obtidos mostraram que não ouve diferença significativa $(\mathrm{p}<0,05)$ para as amostras com 1:4 e 1:2 $(\mathrm{m} / \mathrm{m})$ em sua formulação.

Tabela 1: Propriedades mecânicas da mucilagem precipitada (MP) com a incorporação de diferentes concentrações do plastificante glicerol

\begin{tabular}{cc}
\hline $\begin{array}{c}\text { Proporção }(\mathrm{m} / \mathrm{m}) \\
\text { Glicerol : mucilagem }\end{array}$ & Espessura $(\mathrm{mm})$ \\
\hline $1: 0$ & $0,083 \pm 0,001^{\mathrm{a}^{*}}$ \\
$1: 4$ & $0,094 \pm 0,003^{\mathrm{b}}$ \\
$1: 2$ & $0,100 \pm 0,003^{\mathrm{b}}$ \\
$1: 1$ & $0,137 \pm 0,002^{\mathrm{c}}$
\end{tabular}

Letras iguais na mesma coluna mostram que não diferem significativamente entre si $(\mathrm{p}<$ $0,05)$. $*$ Média \pm desvio padrão. 


\subsection{Propriedades Mecânicas}

O aumento da concentração de glicerol favorece a elevação da deformação na tração dos filmes, e isto provavelmente se deve à capacidade do glicerol em reduzir as interações entre cadeias poliméricas, diminuindo assim a resistência do filme e aumentando a flexibilidade (Sothornvit e Krochta, 2000). Esse efeito tem sido estudado por diversos autores como Ahmadi e colaboradores (2011), que estudaram o efeito da adição de glicerol em filmes de sementes de psílio (Plantago ovata Forsk); eles constaram que o aumento da concentração foi responsável pelo aumento no percentual de alongamento $(\varepsilon \%)$, diminuição da tensão de ruptura $(\sigma)$ e do Módulo de Young (MPa). Em trabalho recente Haq et. al.(2013) avaliaram o efeito de plastificantes ao caracterizarem goma de cordia; o resultado mostrou que a adição de plastificantes (glicerol, sorbitol entre outros) levou acentuados valores de tensão de ruptura $(\sigma)$ e alongamento $(\%)$. No presente estudo o uso do glicerol foi estatisticamente favorável ao aumento do alongamento dos filmes com a maior concentração do plastificante $(1: 1 \mathrm{~m} / \mathrm{m})$ (Tabela 2), apesar de um notável maleabilidade nos filmes com 1:2 (m/m) e redução da tensão de ruptura quando comparados com os filmes sem glicerol. Segundo Oliveira (1996), o módulo de elasticidade ou módulo de Young expressa a relação entre a resistência à tração $(\sigma)$ e porcentagem de alongamento $(\varepsilon)$, e indica a rigidez do filme, ou seja, quanto maior o valor do módulo de Young (Y) mais rígido será o filme. Pode-se observar essa redução $(0,068 \pm$ 0,009) (MPa /\%) nos filmes com maior concentração do plastificante, ocasionando aumento da elasticidade $(73,642 \pm 8,958)(\%)$ e redução da tensão de ruptura $(1,764 \pm 0,127)(\mathrm{MPa})$ quando comparados com os filmes sem glicerol $(17,146 \pm 0,046)(\mathrm{MPa})$ e com 1:4 $(\mathrm{m} / \mathrm{m})$ $(10,249 \pm 0,004)(\mathrm{MPa})$.

Tabela 2: Propriedades mecânicas da mucilagem precipitada (MP) com a incorporação de diferentes concentrações do plastificante glicerol

\begin{tabular}{cccc}
\hline $\begin{array}{l}\text { Proporção }(\mathrm{m} / \mathrm{m}) \\
\text { Glicerol : mucilagem }\end{array}$ & $\varepsilon(\%)$ & $\sigma(\mathrm{MPa})$ & $\mathrm{Y}(\mathrm{MPa} / \%)$ \\
\hline $0: 1$ & $2,122 \pm 0,678^{\mathrm{a}}{ }^{*}$ & $34,479 \pm 2,913^{\mathrm{c}}$ & $17,146 \pm 0,046^{\mathrm{c}}$ \\
$1: 4$ & $1,962 \pm 1,357^{\mathrm{a}}$ & $18,952 \pm 6,758^{\mathrm{a}}$ & $10,249 \pm 0,004^{\mathrm{a}}$ \\
$1: 2$ & $6,922 \pm 3,620^{\mathrm{a}}$ & $11,900 \pm 6,737^{\mathrm{ab}}$ & $5,619 \pm 3,608^{\mathrm{ab}}$ \\
$1: 1$ & $73,642 \pm 8,958^{\mathrm{b}}$ & $1,764 \pm 0,127^{\mathrm{b}}$ & $0,068 \pm 0,009^{\mathrm{b}}$
\end{tabular}

Letras iguais na mesma coluna mostram que não diferem significativamente entre si ( $\mathrm{p}<$ $0,05)$. * Média \pm desvio padrão.

\subsection{Permeabilidade ao vapor de água (PVA)}

Os resultados da variação de massa em função do tempo são mostrados na Figura 1. Observa-se que os valores dos coeficientes de determinação são maiores que 0,97 mostrando a excelente correlação linear. 


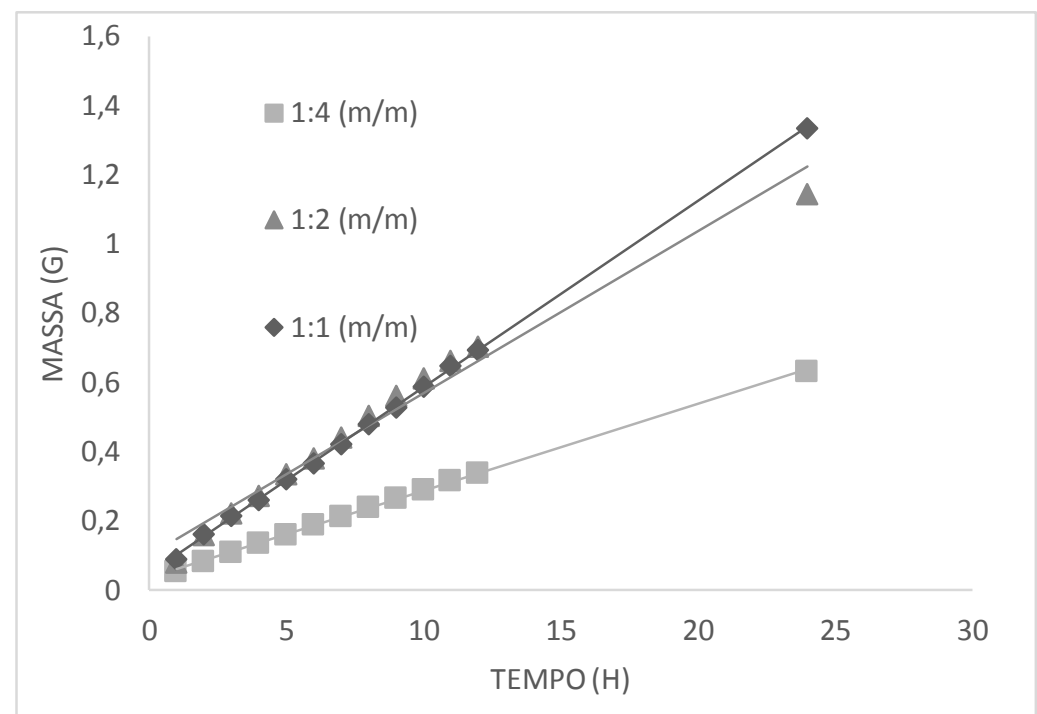

Figura 1- Aumento da massa (g) em função do tempo (h)

Os resultados apresentados acima são descritos pelas seguintes equações:

MASSA $=0,0251 \times \mathrm{TEMPO}+0,0352$,
MASSA $=0,0468 \times \mathrm{TEMPO}+0,1001$,
MASSA $=0,0538 \times \mathrm{TEMPO}+0,0475$,

A maioria dos filmes que possuem glicerol em sua formulação apresentam comportamento linear com a concentração de glicerol adicionada. Os valores da PVA encontrados no presente estudo estiveram na faixa de $0,226-0,992 \mathrm{~g} \mathrm{~mm} / \mathrm{kPa} \mathrm{h} \mathrm{m}^{2}$ para as formulações (1:4, 1:2 e 1:1) de glicerol por massa de mucilagem, e são similares aos relatados por alguns autores na literatura para filmes de biopolímeros. Khazaei et. al (2014) ao caracterizar goma de semente de manjericão, obteve $0,806 \pm 0,01 \mathrm{~mm} / \mathrm{kPa} \mathrm{h} \mathrm{m} \mathrm{m}^{2}$ para filmes com $50 \%$ de glicerol; o presente estudo forneceu o valor $0,636 \mathrm{~g} \mathrm{~mm} / \mathrm{kPa} \mathrm{h} \mathrm{m}^{2}$ para a mesma concentração (1:2 m/m). Muñoz et. al (2012) elaborou filmes contendo mucilagem de chia, proteína isolada e glicerol em diferentes proporções cujo valor de próximos a $0,620 \mathrm{~g} \mathrm{~mm} / \mathrm{kPa}$ $\mathrm{h} \mathrm{m}^{2}$ foi encontrado. Souza et. al. relata o aumento significativo $(\mathrm{p} \leq 0,05)$ em filmes de quitosana $0,1725 \pm 1,25 \times 10^{-3} \mathrm{~g} \mathrm{~mm} / \mathrm{kPa} \mathrm{h} \mathrm{m}^{2}$ e $0,282 \pm 3,33 \times 10^{-3} \mathrm{~g} \mathrm{~mm} / \mathrm{kPa} \mathrm{h} \mathrm{m}^{2}$ para filmes contendo quitosana e glicerol. Na Figura 1 pode-se observar o ganho de massa em função do tempo. O filme com maior concentração de glicerol apresentou maior ganho de massa no decorrer do processo.

\section{CONCLUSÃO}

A mucilagem de Cereus hildmaniannus K. Schum é capaz de formar filmes que, sem adição de plastificante são rígidos e quebradiços. A adição de plastificante mostrou-se necessária de modo a melhorar suas características mecânicas. $O$ filme com maior concentração de glicerol como plastificante mostrou o maior valor de alongamento do filme. Juntamente com este comportamento observou-se um incremento da espessura e da permeabilidade ao vapor de água do filme. 


\section{REFERÊNCIAS}

AHMADI, R.; KALBASI-ASHTARI, A.; OROMIEHIE, A., YARMAND, M. S., \& JAHANDIDEH, F. Development and characterization of a novel biodegradable edible film obtained from psyllium seed (Plantago ovate Forsk). Journal of Food Engineering, v. 109, p. 745-751, 2012.

ASTM. Designation E 96-95: Standard method for water vapor transmission of materials. In Annual book of ASTM standards. Philadelphia: American Society for Testing and Materials, 1995.

ASTM. Standard test method for tensile properties oh thin plastic sheeting, D-882-91. In Annual Book of ASTM; American Society for Testing and Materials, Philadelphia, PA, 1996.

CERQUEIRA, M. A.; LIMA, A. M. P.; SOUZA, B. W. S.; TEIXEIRA, J. A.; MOREIRA, R. A.; VICENTE, A. A. Functional polysaccharides as edible coatings for cheese. Journal Agriculture and Food Chemistry, v.57(4), p.1456-1462, 2009.

COLONETTI, V.C. CARACTERIZAÇÃO DA MUCILAGEM DO FRUTO E CLADÓDIO DE Cereus hildmaniannus K. Schum. Dissertação (mestrado) Universidade Federal de Santa Catarina, Centro Tecnológico, Programa de Pós Graduação em engenharia Química, Florianópolis 2012.

CUQ, B.; GONTARD, N.; CUQ, J.L.; GUILBERT, S. Selected functional properties of fish myofibrillar protein-based films as affected by hydrophilic plasticizers. Journal of Agricultural and Food Chemistry, v. 45, p. 622-626, 1997.

FERREIRA, C. O.; NUNES, C. A.; DELGADILO, I.; SILVA, J. A. L. Characterization of chitosan-whey protein films at acid pH. Food Research International, v. 42, p. 887813, 2009.

GIRISH K JANI, DHIREN P SHAH, VIPUL D PRAJAPATI ETC .Gums and mucilages: versatile excipients for pharmaceutical formulations. Asian Journal of Pharmaceutical Sciences, v. 4, p. 308-322, 2009.

HAQ, M.A.; HASANAIN, A.; AZAM, M. Characterization of edible gum cordia film: Effects of plasticizers. Food Science and Technology, v.55, p.163-169, 2014.

JANI, G. K.; SHAH, D. P.; PRAJAPATI, V. D.; JAIN, V. C. Gums and mucilages: versatile excipients for pharmaceutical formulations. Asian Journal of Pharmaceutical Sciences, v. 4, 2009.

KHAZAEI, N.; ESMAIILI, M.; DJOMEH, Z. E.; GHASEMLOU, M.; JOUKI, M.; Characterization of new biodegradable edible film made from basil seed (Ocimum basilicum L.) gum. Carbohydrate Polymers, v. 102, p. 199-206, 2014.

KROCHTA, J.M. Proteins as raw materials for films and coatings: definitions, current status, and opportunities. In Protein-based films and coatings; New Jersey. Editora: Aristippos Gennadios; Boca Raton, p. 367, 2002. 
MALI, S.; GROSSMANN, M. V. E.; YAMASHITA, F. Filmes de amido: produção, propriedades e potencial de utilização. Semina: Ciências Agrárias, v. 31, p. 137-156, 2010.

MUÑOZ, L. A.; AGUILERA, J. M.; RODRIGUEZ-TURIENZO, L.; COBOS, A.; DIAZ, O. Characterization and microstructure of films made from mucilage of Salvia hispanica and whey protein concentrate. Journal of Food Engineering, v. 111, p. 511-518, 2012.

OLIVEIRA, A.F.; SOLDI, V.; COELHO, C.M.M.; MIQUELOTO, A.; COIMBRA, J. L.M. Preparação, caracterização e propriedades de filmes poliméricos com potencial aplicação no recobrimento de sementes. Química Nova, v. 32, p. 1845-1849, 2009.

SARANTÓPOULOS, C. I. G. L.; OLIVEIRA, L. M.; PADULA, M.; COLTRO, L.; ALVES, R. M.V.; GARCIA, E. E. C.; Embalagens Plásticas Flexíveis - Principais Polímeros e Avaliação de Propriedades. Campinas: Editora CETEA/ITAL, p. 267, 2002.

SOTHORNVIT, R.; KROCHTA, J. M. Plasticizer effect on oxygen permeability of betalactoglobulin films. J. Agric. Food Chem. v. 48, p. 6298, 2000.

SOUZA, C. V., MONTE M. L., E PINTO. A. A. L., Effect of carp (Cyprinus carpio) oil incorporation on water vapour permeability, mechanical properties and transparency of chitosan. International Journal of Food Science and Technology, v. 48, p. 1309-1317, 2013. 